\title{
LEARNING TO NOTICE: A STUDY OF PAKISTANI STUDENT TEACHERS' REFLECTION ON THEIR CLASSROOM VIDEOS
}

\author{
Samina Naseem \\ Assistant Professor, \\ Department of Education, Fatima Jinnah Women University, \\ Punjab, Pakistan \\ Email: samina.naseem05@gmail.com
}

\author{
Afshan Huma \\ Assistant Professor, \\ Department of Educational Planning, Policy Studies and Leadership, \\ Allama Iqbal Open University, \\ Islamabad, Pakistan \\ Email: afshan.huma@aiou.edu
}

\section{Salma Nazar Khan}

Assistant Professor,

Department of Education, Fatima Jinnah Women University,

Punjab, Pakistan

Email: salmanazarkhan@gmail.com

\begin{abstract}
This paper examines the use of videos of Student Teachers' (STs') classrooms to develop their noticing skills as teachers in the Pakistani context. Data were collected from twenty-four students during two teaching practicums in the VII and VIII semesters of a four-year B.Ed program offered in Pakistan's public university. Analysis of STs' videos, reflections, and classroom observations show that the STs focused on discipline issues in their classroom during the VII semester. The following semester increased attention to their teaching was observed in very few STs. In addition, none of the STs focused on students' thinking in the classroom or connected events directly with larger principles of teaching per se. The findings highlight the importance of using videos to develop necessary skills in prospective teachers and underscore the significance of developing faculty members professionally who teach B.Ed programs with new ideas of teaching and learning.
\end{abstract}

\section{KEYWORDS}

Teaching videos, reflective skills, student teachers, learning to notice framework 
INTRODUCTION

Since the 1960s, teacher educators have used teaching videos in teacher preparation programs (Santagata \& Guarino, 2011; Sherin \& van Es, 2005). Videos are considered as means to help teachers reflect on their interactions in the classroom (Sherin \& Han, 2004). For example, van Es and Sherin (2010) focused on video clubs to understand mathematics teachers' thinking and practice. Santagata and Guarino (2011) used videos to study and discuss pre-service mathematics teachers' "orientations, knowledge, and skills for analyzing and reflecting on mathematics teaching in ways that generate knowledge for improvement" (p.133). Researchers have argued in favor of using videos to teach STs to develop their reflective teaching-learning skills by noticing the various dynamics of the classroom, thus improving their teaching practice (e.g. (Sherin, 2001; Wang \& Hartley, 2003). In this paper, teaching and practice are considered to have the same meaning. i.e., their lesson delivery, interaction with students, and responding to students' responses. Most studies have focused on mathematics and literacy teachers (e.g., Santagata \& Guarino, 2011; van Es \& Sherin, 2008, 2010; Sherin \& van Es, 2005). This paper examines the use of classroom teaching videos of STs [during teaching practicum] to 'notice' various aspects of teaching practice, thus developing their reflective teaching-learning skill as teachers. These STs taught varied subjects such as English, Urdu, math, general science, social studies, and religion (Islamiyat).

\section{Learning to notice Framework: Using video in developing reflective skills}

Many researchers (e.g., Berliner, 1988; Mason, 2002) consider the ability to notice and interpret what is happening in the classroom as one of the significant components of teacher expertise. Sherin and van Es (2005) explored the meaning of a teacher's ability to "notice" by using video as a tool. According to Coffey (2014), "Video is regarded as a tool that can help teacher education students develop the ability to notice what is occurring in the classroom" (p. 88). Other researchers (e.g., Baecher, McCormack, \& Kung, 2014; Trip \& Rich, 2012) suggest that reflecting on one's teaching video is an excellent way of self-evaluation. For example, Trip and Rich (2012) concluded that after teachers used videos to reflect, they were able to: "(a) identify gaps between their beliefs about good teaching and their actual teaching practices, (b) articulate their tacit assumptions and purposes about teaching and learning, (c) notice things about their teaching that they did not remember, (d) focus their reflections on multiple aspects of classroom teaching, and (e) assess the strengths and weaknesses of their teaching." (p. 729). In other words, it can be argued that videos of one's teaching can help teachers to notice. It is essential to introduce STs during teaching practicum to help them develop their skills to reflect. Sherin and van Es (2005), in their seminal work on learning to notice, maintained that noticing comprises of three components - (1) highlighting a significant event, (2) using their knowledge to explain the event, and (3) connecting the event with the larger principles of teaching. In this study, these three 
components are applied to STs: what events STs attend to, their use of the knowledge about the context to explain the event, and their connection with the larger principles of teaching they have learned during the coursework. Inviting STs to evaluate their performance can help them to become active in the process of developing professionally as teachers (Baecher, McCormack, \& Kung, 2014; Towndrow \& Tan, 2009). Teaching videos provide unique opportunities for STs to critically analyze their teaching and their peers' teaching.

\section{Our roles as researchers}

All three authors were engaged in this research on different levels. The primary author played a crucial role in guiding this research and collecting data. The other two authors reflected upon data, and they all mutually worked on analysis and interpretation of data to draw inferences. None of the authors have had any formal training to evaluate teaching videos with respect to the 'Learning to Notice' framework. However, our exposure and research experience in international universities during doctoral studies gave us an understanding of how to guide STs. Our experiences of using teaching videos as a tool without any professional development provide implications for teacher educators, which are discussed later in the paper.

The role of the primary author as a practicum supervisor was to develop STs' reflections by using their teaching videos and help them 'notice' significant aspects. For example, while sharing one ST's teaching with her classmates, the primary author emphasized how the ST specifically selected students whose answers were incorrect or presented a misconception. The STs were given the liberty to choose any twominute clip they thought was important. University supervisors play an essential role in developing STs' skills to reflect with or without videos. According to Baecher, McCormack, and Kung (2014), by engaging STs "metacognitively" to evaluate their teaching, supervisors provide STs the opportunities to develop professionally and to understand the underlining complexities of being a teacher and classroom teaching. We agree with researchers (e.g., Baecher, McCormack, \& Kung, 2014; Dangel \& Tanguay, 2014; Danielowich \& McCarthy, 2013) who argued that supervisors are reluctant to use videos because they do not have the formal training to review videos in productive ways to help STs.

\section{RESEARCH OBJECTIVE}

1. This research aimed to use STs' teaching videos to document what they "notice" as teachers and probe their thinking to develop their reflective skills as teachers.

\section{RESEARCH QUESTION}

1. What aspects of teaching and learning do STs notice in their teaching videos? 


\section{RESEARCH METHODOLOGY}

Qualitative in nature, data for this study comes from a two-semester (eight months) long set of reflections and videos from twenty-four STs studying in a public university for women.

\section{Population \& Sampling}

Twenty-three students were sent to two public schools for a ten-day teaching practicum in their VII semester. In the VIII semester (their last semester in a four-year B.Ed Hons. Degree Program), twenty-four students were sent to two missionary schools for monthlong teaching practice.

\section{Data Sources of the Study}

Each student was observed twice in both semesters by the primary author. After the observation, each student met the primary author to discuss and reflect upon her teaching. However, the STs were asked to submit a short clip of their teaching in the VII semester and a whole class video in the VIII semester, reflecting on their teaching as a part of their portfolios. The other source of data for this study is classroom observations. When the idea was introduced in the VII semester, the STs were given two main guiding questions. 1) What do you see in the video? 2) Why is it important for you to mention? After their submission, the first author met STs in a group to discuss what she noticed in the video and what was significant about that aspect. In the following semester, only one school allowed students to record teaching videos, reducing the number to ten STs, out of which only seven submitted their teaching videos and reflections.

This paper first discusses the reflections of STs in the VII semester. It then focuses explicitly on reflection on teaching videos and observations of those seven students who submitted videos in VIII semesters.

\section{DATA ANALYSIS AND RESULTS}

Data analysis was done in two cycles (Saldana, 2010). First, all the reflections were read to get a general sense of what STs had written. In the second cycle, the reflections were coded. The "learning to notice" framework provided a set of provisional codes such as an event, type of event, explanation, teaching principles, etc. (Miles \& Huberman, 1994). We also used a grounded approach to code and identified categories that emerged from the data (Corbin \& Strauss, 2008). The codes were put under three themes of the "learning to notice" framework (as shown in Table 1). Grammatical mistakes in the quotes used are intentionally left to help the readers understand the writing ability of most of the STs. This has implications for teacher educators worldwide, where English is not the native language. 


\section{FINDINGS AND DISCUSSION}

Table 1 provides an overview of findings grounded in the 'learning to teach framework' based on the provisional themes followed by a discussion of emergent findings of this study presenting implications for teacher education.

Table 1. An overview of the aspects focused by STs

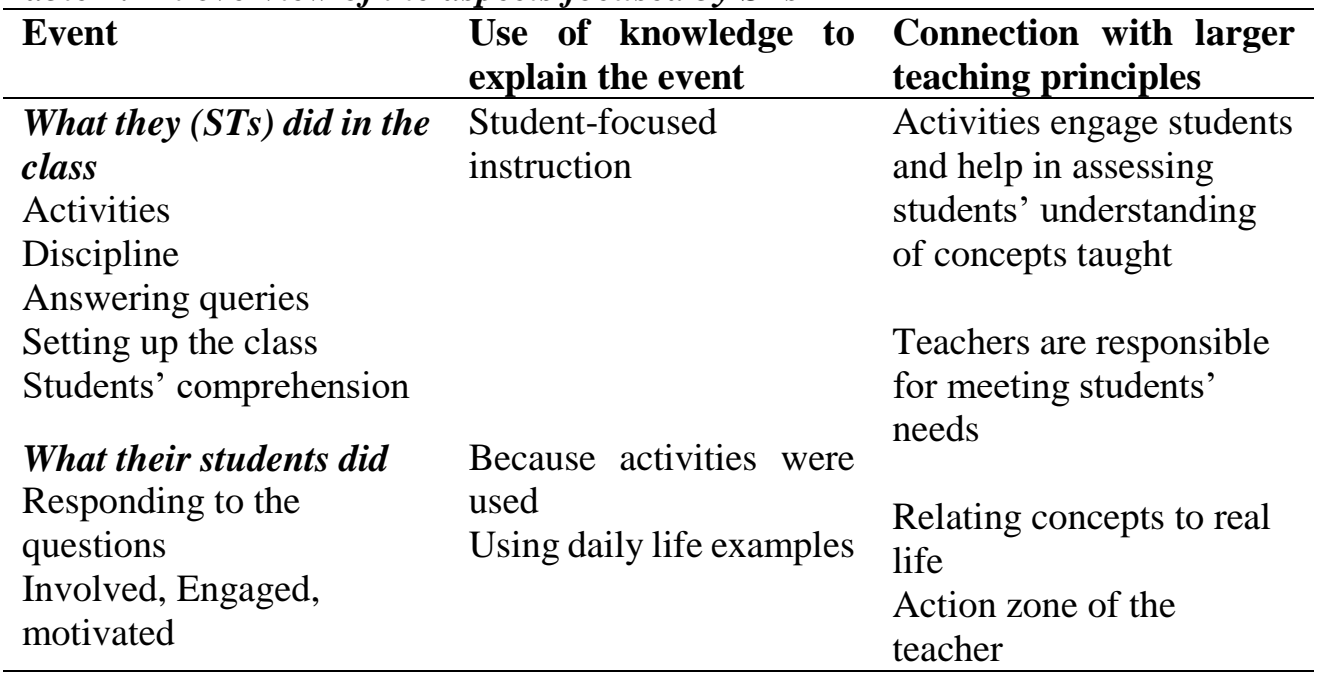

\section{Events focused by the STs}

The STs were given two guided questions in the VII semester. The reflections of the STs presented an unanticipated influence on what the STs noticed in their videos (discussed later) in contrast to what the literature suggests about learning to notice. Research (for example, van Es \& Sherin, 2002; van Es \& Sherin, 2008) maintains that teachers cannot respond to all happening in the classroom. The events teachers select to attend and respond termed as "call-out" or "check-points" (Frederiksen, 1992 \& Leinhardt, Putnam, Stein, \& Baxter, 1991 as cited in van Es \& Sherin, 2002). These callouts inform teachers to revisit and realign their instructional plans. Interactions among students, such as "working closely, explaining ideas to each other..." (van Es \& Sherin, 2002, p. 575), motivation to learn, and assessing students' understanding revolve around the idea of reform-minded teaching. Teachers should connect these checkpoints to the larger teaching and learning principles. Most of the STs selected video clips, which primarily focused on what they as teachers did in the classroom and how their students were engaged and motivated in their designed activities rather than focusing on students' responses and understanding.

Therefore, the data events focused on video reflections of STs are categorized into a) what the STs did and b) what their students did in the classroom. We argue that the 
STs did not understand the complexity of the relationship that exists among their practices in the classroom, management, and the activities given (Kagan, 1992; Melnick \& Meister, 2008), thus limiting STs to notice merely what they did, or their students did in the classroom rather than students' learning (Melnick \& Meister, 2008).

While reflecting on the videos, the STs reflected upon setting up of the classroom ("putting up charts," "writing meanings on the board"), the activities they did ("experiment," "flashcards," "activities"), and overall discipline of the classroom ("sat in their seats," "raised their hands"). For example, one of the STs mentioned, "I prepared activities, charts, pre \& post-tests, flashcards and models for making my teaching more interesting and interactive for students." Regarding discipline, one of the STs explicitly mentioned, "They [students] raised their hands, and I heard their answers one by one." Only one of the STs said the term "students' comprehension" but did not elaborate further the meaning of the term 'used.' Discipline is considered as one of the significant concerns of teachers (others being time management, parents' involvement \& preparation, Britt as cited in Melnick \& Meister, 2008).

The STs, while describing what their students did in the videos, most of the STs used terms such as "students were engaged," or "...responding to questions," or "...were interested / enjoying" their "lectures." For example, one ST wrote, "I chose this video because, in this video, I am getting responses of the students." They also unanimously described their teaching as a "lecture" rather than interactive teaching. These findings echoed van Es and Sherin's (2002; 2010) arguments that teachers choose those events/ situations, that direct their attention, referring to them as "highlighting." These findings are also consistent with the research done by Verlaan and Verlaan (2015). They found that pre-service teachers consistently focused on their behavior, body language, pedagogy, and students' involvement rather than students' responses.

On another note, Tripp and Rich (2012) mentioned one of the benefits of video-based self-reflection is one's ability to "assess strengths and weaknesses of their teaching" (p.729). The analysis of the video reflections by the ten STs and their observations during the VIII semester revealed that the events focused on did not change. Reflections of the STs mainly focused on the strengths rather than areas of improvement. Two of these STs were able to make connections with the larger teaching principles (discussed below). Only one ST mentioned that the "students are distracted" in her video and that it was her "fault" that she could not engage students. She mentioned that she had learned what areas she needed to improve from her video but did not elaborate on the areas or give concrete examples.

Possessing the ability to notice and interpret classroom situations is considered one of the critical components of a teacher's expertise (Berliner, 1988; van Es \& Sherin, 
2010). Also, in the learning to notice framework, analyzing what STs noticed is as significant as what STs chose to notice. During our deliberations about the data interpretations, we realized that the STs focused on the events frequently discussed in their on-campus meetings with the first author. We argue that the unanticipated influence of the primary author's discussion on what the STs noticed is a classic example of "teachers influence on students' thinking" (van Es \& Sherin, 2002). We further argue that it is a possibility that STs intentionally chose those events to impress the supervisor and to get better grades.

\section{Using knowledge to explain the event}

The finding of this study reveals that the STs were rational yet did not possess the experience to use the knowledge to interpret and explain various events happening in their classroom (Berliner, 1988). The reflections on videos showed one common explanation that their students responded or were engaged because the STs used "a number of activities" or "did experiments" in the classroom. For example, one of the STs wrote, "Students are very interested in this lesson because there were many activities, so they [students] were taking [an] interest." Another ST said that activities were helpful in "gaining students' attention" in the classroom. Few other STs mentioned that their students were involved because they gave "real-life examples" during their lessons. The video reflections in the VIII semester were no different from those submitted in the VII semester. Only one of the STs specifically used the term "student-centered instruction" to explain her students' involvement. However, the STs did not provide explanations of students' attention or involvement based on their own "knowledge of the subject matter, knowledge of how students think about the subject matter, and knowledge about the context where they were teaching" (van Es \& Sherin, 2002).

The primary author deliberated that the consistent pattern to describe the knowledge utilization in explaining the events was again influenced by the on-campus discussions. The STs referred to the common aspects of discussion such as students' engagement, use of relevant activities, and use of real-life examples. The primary author believes that she missed an opportunity to further STs thinking by asking simple questions, "why do you think students are engaged or how activities and real-life examples have engaged students?" Another explanation why STs failed to explain events can be attributed to their lack of experience to make sense of what they observed (Berliner, 1988).

We also argue that it could be the fact that not all STs were good in spoken and written English, which might have limited them to express their ideas, views, and explanations. It might have been easier for them to write about aspects already discussed and vocabulary already used in the meetings, rather than pointing out new aspects and then 
explaining them. This highlights one of the critical issues that STs confront, whose first language is not English and they have not studied in English medium institutions. Yet, teacher education courses and assignments are in English, thus making it challenging for STs to express their ideas in writing.

\section{Connections with larger teaching principles}

Most of the STs connected activities with the idea that activities provide opportunities to engage and motivate students. Examples from real-life make abstract concepts clear and meaningful for students. Two of the STs also contended that activities help assess students' understanding of the concepts. Similarly, one of the STs mentioned that she was "responsible for meeting students' needs." The STs provided a "literal description" of what they saw and thought was happening in the class (Berliner, 1988; van Es \& Sherin, 2002). At this stage, the primary author again missed an opportunity to encourage the STs to ask themselves a straightforward question, "What is this a case of?" (Shulman 1996 as cited in van Es \& Sherin, 2002, p. 574). Responding to this simple question could have helped the STs review the events as connected to a principle of teaching and learning, rather than a separate independent event (van Es \& Sherin, 2002). Furthermore, the STs did not mention National Standards for Teachers in Pakistan (Ministry of Education, 2009); specifically, the discussions around using activities for making learning exciting and meaningful for students were an essential part of supervisor- STs on-campus meetings.

Another finding underlines one of the STs' abilities to assess the action zone while reflecting on her teaching video. In her reflection, she particularly pointed out that she was focusing only on the students sitting in the front rows rather than the whole class. Similarly, Cuseo, Fecas, and Thompson (2007) emphasized that the teacher's focus area in the classroom is the front rows or the middle rows, which they referred to as teachers' attentiveness. The ST was able to explain the distraction of her students as a result of her lack of attention. Since only one student mentioned the teacher action zone, the supervisor (primary author) later realized that she missed an opportunity to further discuss teachers' attentiveness as an essential aspect of classroom teaching.

\section{CONCLUSIONS}

In summary, the reported findings indicate that videos are an effective tool in developing reflective skills in STs in almost all subjects, not just math and literacy. Many of the STs saw video as a way of professional development (van Es \& Sherin, 2010). However, they focused more on the aspects frequently discussed by their supervisor during on-campus meetings. Such a following of supervisor's discussion points by STs suggests that supervisors may add the aspects into their discussions, which they want their STs to focus on. Thus, making the guidance more thoughtful, deliberate, specific, and focused on important teaching areas such as students' 
responses to direct STs' attention to students' thinking. It is also concluded that formal training of teacher educators to use videos as a reflective tool in enhancing their learning to notice skill in more productive ways is another crucial aspect to focus on. The findings of this study signify the learning to notice framework in improving reflective teaching-learning skills, yet more detailed studies are required. The videos were introduced in the VII semester and continued in the VIII semester in this study. Further studies in which videos are introduced in the first teaching practicum and followed up in the next three teaching practicums may provide a deeper understanding of how videos support the development of STs' reflective teaching-learning skills.

\section{RECOMMENDATIONS}

As argued previously in this paper, supervisors have an essential role to play, whether to help STs develop reflective teaching-learning skills or give them feedback for improvement. Since the primary author did not have any training for using videos as a tool, she constantly missed instances that could have helped develop reflective teaching-learning skills in STs. Carver and Katz (2004) termed this inability to focus on the issues STs face by new mentors as "missed" opportunities. The primary author is a seasoned teacher, yet she was new to using videos to mentor STs.

One important implication of this study is that if teacher educators avoid discussing a few specific aspects of teaching, then STs might be more open to noticing new aspects in their teaching. The primary author did not notice that [on-campus] pre-and-post video reflection discussion would result in STs' choice to select only those video clips that would predominantly reflect the discussed aspects. Again, if such an influence was anticipated, teacher educators can deliberately choose teaching aspects such as students' responses and thinking in post-observation discussions (POD). Furthermore, in countries where English is not the native language, teacher educators must schedule individual POD to provide opportunities to STs to share their explanations in their native language to unpack misconceptions and express their perspectives to effectively connect the classroom events with the larger teaching principles. Baecher, McCormack, and Kung (2014) found that supervisors were "unsure" about using videos in fostering reflective skills in STs. To some extent, the primary author underwent a similar experience. STs' reflections also suggest that if supervisors want them to focus on some specific area, they might want to bring those aspects up frequently in their discussions and meetings with STs, thus enabling them to reflect on those aspects. More importantly, taking such measures can make the unanticipated influence; more focused and anticipated, for instance, discussing teachers' action zone. Another important implication of these findings is the professional development of faculty in using tools such as videos in their teaching to help STs reflect on their teaching. It goes without saying that if the primary author had some formal training, the video reflections would have been more thorough and more explicit. 
Another critical aspect was POD with each of the ST is important to analyze their classroom teaching and provide them an opportunity to take part in their critical evaluation (Baecher, McCormack, \& Kung, 2014). There was no individual POD organized with the STs. The primary author watched the STs' videos collectively and discussed common aspects among all the STs' teaching videos. We agree to the fact that individual PODs can be time-consuming in many ways. First, PODs could not be scheduled during teaching practicum due to the lack of time availability. Coffey (2014) and Cavanagh and Prescott (2010) found that learning to reflect can intimidate STs. Learning to reflect on their teaching is one of the important skills STs must develop (Coffey, 2014), especially while interacting with real classroom situations during practicum. Second, the primary author could not realize the significance of PODs until we started analyzing the data. Therefore, teacher educators need to make sure that they should have individual POD with their STs along with the video. Individual POD is central to using video as a tool in the same way as a separate discussion is important after live class observation. Schwille (2008) accentuated the similar finding that focusing on one-to-one PODs helps probe and push STs' thinking to areas supervisors want them to focus on.

Although videos are an excellent tool to help STs reflect, they cannot be a substitute for face-to-face classroom observation and have some limitations. First, videos limit the opportunity for supervisors to observe their STs' on-spot responses if they are not in front of the camera. Moreover, when any of the STs were recording her class, the primary author preferred observing the STs who were not recording. Again, opportunities to observe STs before watching their videos were missed, thus limiting the feedback to what she watched in their videos. Hence, teacher educators who plan to use videos as a tool must observe the ST get a holistic picture of what happened in the classroom, rather than solely depending on the video recording. Baecher, McCormack, and Kung (2014) reported similar observations in their research. Second, as Baecher, McCormack, and Kung (2014) suggested, STs can be uncomfortable about recording their teaching or become conscious about how they sound while evaluating their teaching and asking their peers to give feedback on their videos. However, the STs in this study were close to each other as a group, and they were confident about their teaching and giving each other feedback and support. The STs mentioned that video recording was a "good experience" to give and receive feedback from peers and considered it "professional development." This implies that a strong understanding among STs facilitates self-recording and peer-reviewing. Therefore, teacher educators must develop strong bonding among STs before using videos as a tool. 


\section{REFERENCES}

Baecher, L., McCormack, B., \& Kung, S. C. (2014). Supervisor use of video as a tool in teacher reflection. The Electronic Journal for English as a Second Language, 18(3), 1 - 17. Available at http://www.tesl-ej.org/pdf/ej71/a5.pdf

Berliner, D. (1988). The Development of Expertise in Pedagogy. AACTE Publications, One Dupont Circle, Suite 610, Washington, DC

Carver, C. L., \& Katz, D. S. (2004). Teaching at the boundary of acceptable practice: What is a new teacher mentor to do? Journal of Teacher Education, 55 (5), 449-462.

Cavanagh, M., \& Prescott, A. (2010). The growth of reflective practice among three beginning secondary mathematics teachers. Asia-Pacific Journal of Teacher Education, 38(2), 147- 159. http://dx.doi.org/10.1080/13598661003678968

Coffey, A. M. (2014). Using Video to Develop Skills in Reflection in Teacher Education Students. Australian Journal of Teacher Education, 39(9), 86-97.

Corbin, J. \& Strauss, A. (2008). Basics of qualitative research, $3^{\text {rd }}$ edition. Thousand Oaks, CA: Sage.

Cuseo, J., Fecas, V. S., \& Thompson, A. (2007). Thriving in college \& beyond: Research-based strategies for academic success and personal development. Dubuque, IA: Kendall/Hint.

Dangel, J. R., \& Tanguay, C. (2014). "Don't leave us out there alone": A framework for supporting supervisors. Action in Teacher Education, 36(1), 3-19.

Danielowich, R. M., \& McCarthy, M. J. (2013). Teacher educators as learners: How supervisors shape their pedagogies by creating and using classroom videos with their student teachers. Action in Teacher Education, 35(3), 147-164.

Kagan, D. M. (1992). Professional growth among preservice and beginning teachers. Review of Educational Research Summer, 62(2), 129-169.

Saldana, J. (2010). The coding manual for qualitative researchers. Los Angeles: Sage Publishers.

Santagata, R., \& Guarino, J. (2011). Using video to teach future teachers to learn from teaching. ZDM Mathematics Education, 43, 133-145. DOI 10.1007/s11858-010-0292-3

Schwille, S. A. (2008). The professional practice of mentoring. American Journal of Education, 115 (1), 139-167.

Sherin, M. G. (2001). Developing a professional vision of classroom events: Teaching elementary school mathematics. In Beyond classical pedagogy: Teaching elementary school mathematics (pp. 75-93). Hillsdale, NJ: Erlbaum.

Sherin, M.G. \& Van Es, E.A. (2005). Using video to support teachers' ability to notice classroom interactions. Journal of Technology and Teacher Education, 13(3), 475-

491.

Sherin, M. G., \& Han, S. (2004). Teacher learning in the context of a video club. Teaching and Teacher Education, 20,163-183.

Mason, J. (2002). Researching Your own practice: The discipline of noticing. London: Routledge Falmer.

Melnick, S. A., \& Meister, D. G. (2008). A comparison of beginning and experienced teachers' concerns. Educational Research Quarterly, 40- 56.

Miles, M.B., \& Huberman, A. M. (1994). Qualitative data analysis: An expanded sourcebook, 
2nd Edition. Thousand Oaks, CA: Sage.

Ministry of Education, (2009). National professional standards for teachers in Pakistan. Islamabad: Government of Pakistan. Retrieved September 16, 2013 from http://unesco.org.pk/education/teachereducation/files/National\%20Professional\%20S tandards\%20for\%20Teachers.pdf

Towndrow, P. A., \& Tan, K. (2009). Teacher self-evaluation and power. Teacher Development, 13(3), 285-295.

Tripp, T., \& Rich, P. (2012). The influence of video analysis on the process of teacher change. Teaching and Teacher Education, 28(5), 728-739.

van Es, E. A., \& Sherin, M. G. (2010). The influence of video clubs on teachers' thinking and practice. Journal of Math Teacher Education, 13, 155-176. DOI 10.1007/s10857009-9130-3

van Es, E. A., \& Sherin, M. G. (2008). Mathematics teachers" "learning to notice" in the context of a video club. Teaching and Teacher Education. 24 (2), 244-276.

van Es, E. A., \& Sherin, M. G. (2002). Learning to notice: Scaffolding new teachers' interpretations of classroom interactions. Journal of Technology and Teacher Education, 10(4), 571-596.

Verlaan, W.E., \& Verlaan, S. (2015). Using video-reflection with pre-service teachers: A cautionary tale. In E. Ortlieb, L. Shanahan, \& M. McVee (Eds.), Video reflection in literacy teacher education and development: Lessons from research and practice (pp. 151-171). Bingley, UK: Emerald Group.

Wang, J. \& Hartley, K. (2003). Video technology as a support for teacher education reform. Journal of Technology and Teacher Education, 11(1), 105-138. 